\title{
Implications of Self-Potential Distribution for Groundwater Flow System in a Nonvolcanic Mountain Slope
}

\author{
Tada-nori Goto, ${ }^{1}$ Kazuya Kondo, ${ }^{2}$ Rina Ito, ${ }^{2}$ Keisuke Esaki, ${ }^{2}$ Yasuo Oouchi, ${ }^{2}$ \\ Yutaka Abe, ${ }^{3}$ and Maki Tsujimura ${ }^{3}$ \\ ${ }^{1}$ Graduate School of Engineering, Kyoto University, C1-1-113, Kyodai-Katsura, Nishikyo, Kyoto 615-8540, Japan \\ ${ }^{2}$ Department of Environmental Earth Sciences, Aichi University of Education, 1 Hirosawa, Igaya-cho, Kariya, \\ Aichi 448-8542, Japan \\ ${ }^{3}$ Graduate School of Life and Environmental Sciences, University of Tsukuba, 1-1-1 Tennodai, \\ Tsukuba 305-8572, Japan \\ Correspondence should be addressed to Tada-nori Goto, goto.tadanori.8a@kyoto-u.ac.jp
}

Received 10 August 2011; Revised 25 December 2011; Accepted 18 January 2012

Academic Editor: Tsuneo Ishido

Copyright (C) 2012 Tada-nori Goto et al. This is an open access article distributed under the Creative Commons Attribution License, which permits unrestricted use, distribution, and reproduction in any medium, provided the original work is properly cited.

\begin{abstract}
Self-potential (SP) measurements were conducted at Mt. Tsukuba, Japan, which is a nonvolcanic mountain, to infer groundwater flow system in the mountain. Survey routes were set around the northern slope, and the reliability of observed SP anomaly was checked by using SP values along parallel survey routes; the error was almost within $10 \mathrm{mV}$. The FFT analysis of the spatial SP distribution allows us a separation of raw data into two components with shorter and longer wavelength. In the shorter (altitudinal) wavelength than $\sim 200$ meters, several positive SP peaks of more than $100 \mathrm{mV}$ in magnitude are present, which indicate shallow perched water discharges along the slope. In the regional SP pattern of longer wavelength, there are two major perturbations from the general trend reflecting the topographic effect. By comparing the SP and hydrological data, the perturbation around the foothill is interpreted to be caused by heterogeneous infiltration at the ground surface. The perturbation around the summit is also interpreted to be caused by heterogeneous infiltration process, based on a simplified numerical modeling of SP. As a result, the SP pattern is well explained by groundwater flow and infiltration processes. Thus, SP data is thought to be very useful for understanding of groundwater flow system on a mountain scale.
\end{abstract}

\section{Introduction}

Spatial distribution of self-potential or spontaneous potential (SP), which is time-invariant natural electrical potential, has been observed at the ground surface along a topographic slope. In general, a negative correlation between altitude and SP value along a slope is reported (e.g., [1-3]), which is called as terrain effect or topographic effect on SP. For example, Sasai et al. [3] have found relatively high SP values at the foothills of the Miyake-jima volcano, decreasing toward the middle altitude of the mountain. The SP profile is well correlated with the topographic profile, and the mean coefficient of topographic effect was $-1.07 \mathrm{mV} / \mathrm{m}$ in the case of the Miyake-jima volcano.

Topographic effect on SP is thought to be caused by subsurface fluid flow along the slope through electrokinetic coupling (e.g., [4]). In rock-water systems, the flow of groundwater can drag excess electrical charges located in the close vicinity of the pore water/mineral interface in the electrical double layer with it, resulting in macroscopic electric current called as streaming current or drag current and the development of electric potential called as streaming potential in the direction of fluid flow (e.g., $[5,6])$. Because the zeta potential, characteristic potential difference across the electrical double layer, is commonly negative for typical crustal rocks in water of $\mathrm{pH}$ higher than $\sim 2$ [6], the pore fluid flow carries positive charges with it; so a negative correlation between the hydraulic head and the streaming potential is expected. Yasukawa and Mogi [7] conducted numerical calculations of groundwater flow and associated streaming potential and confirmed a negative correlation between the altitude and SP value, which has observable amplitude on 
the slope surface. Although SP can be generated by other effects such as thermoelectric coupling [8], electrochemical effects (diffusion potential, redox potential, etc.; e.g., $[8,9]$ ), SP along a mountain slopes is thought to be mainly caused by the electrokinetic effects.

On the basis of the topographic effect, a number of attempts to estimate hydrological features along mountain slopes have been made. For example, Fournier [10] assumed that main SP sources were aligned on water table and tried to estimate the water table elevation using SP data taken at the ground surface. Revil et al. [11] developed a sophisticated method for water table estimation; they inferred the water table elevations below a slope using an inverse technique with the observed SP data. Linde et al. [12] modeled both SP sources in the vadose zone and along the water table and tried to estimate the water table below a slope more precisely. The SP measurement is nonintrusive, quick, and inexpensive; therefore, these benefits tend to accelerate the applications of the SP method to groundwater studies, engineering, and environmental investigations.

There is still some debate, however, about the origin of topographic effect on SP along mountain slopes. Previous studies adopt very simple assumptions of hydrological process. Fournier [10] and Revil et al. [11] excluded the contribution of streaming current associated with downward flow of vadose-zone water, which was taken as the primary source for SP generation by Aubert and Atangana [13]. Although Linde et al. [12] considered both SP sources in the vadose and underlying water-saturated zones, they assumed a homogeneous vadose zone and uniform infiltration at the ground surface. However, numerical studies (e.g., [14]) suggest that complicated downward liquid flow in the vadose zone will make complicated SP pattern on the ground surface.

For small-scale slopes, less than $100 \mathrm{~m}$ in length, Ernstson and Scherer [15] suggest various causes of SP anomalies along the slopes: biological root activity, lateral water movements in alternating permeable and impermeable layers, discharge of perched-water aquifers, and infiltration and evapotranspiration together with groundwater recharge. However, the origins of SP along a larger-scale slope (e.g., a few $\mathrm{km}$ in length) have not been discussed enough. Detailed interpretation of topographic effect on mountainscale SP pattern is useful to apply the SP method to estimate subsurface fluid motions, especially in volcanoes. As many former studies said [3, 16-19], SP anomalies of positive polarity are frequently found around volcano summits and near fumaroles. In order to discuss such SP anomalies, knowledge of SP distribution caused by topographic effect is necessary as a basis.

In order to discuss possible causes of SP along a mountain slope, comparison between the SP pattern and hydrological data along the slope is required, but few field studies were reported. In this study, we investigate selfpotential distribution around the northern slope of $\mathrm{Mt}$. Tsukuba, located in Japan, where extensive hydrological studies have been carried out. Mt. Tsukuba mainly consists of granitic basement, so that the SP distribution along Mt. Tsukuba will be a typical example of topographic

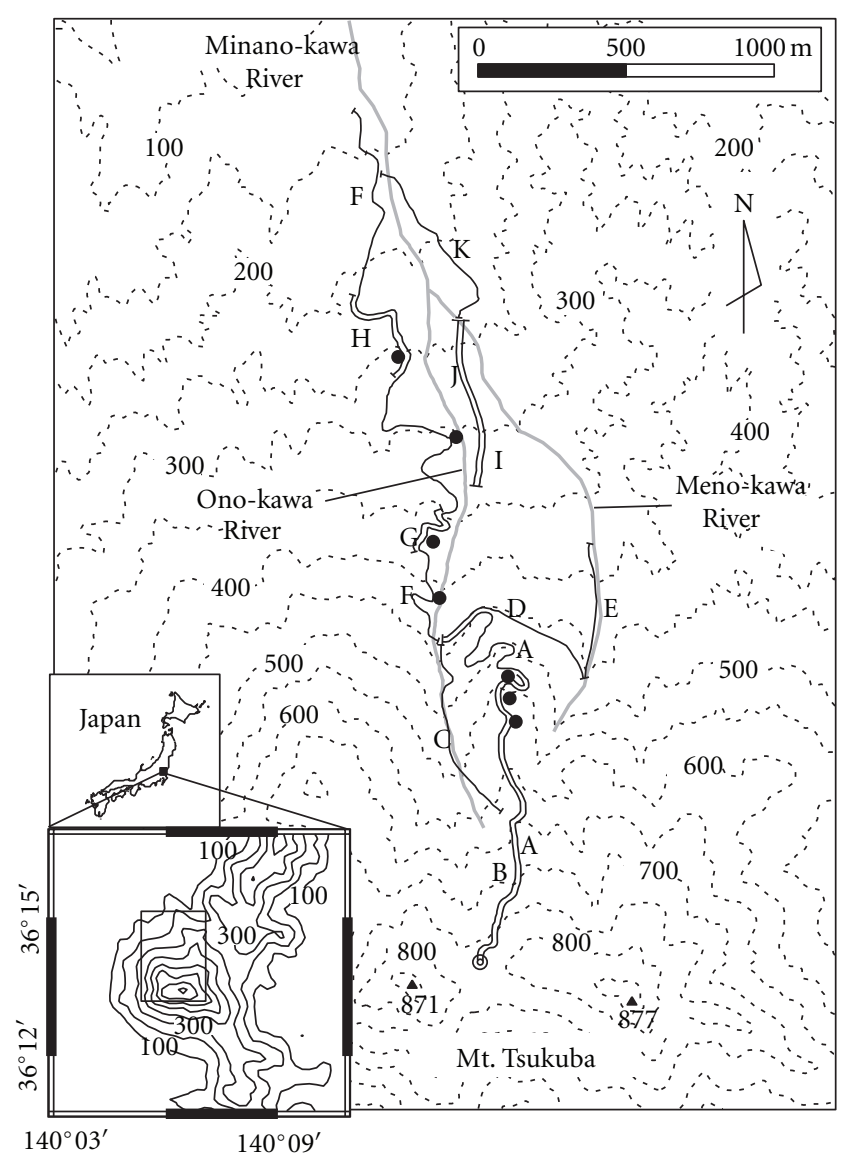

Figure 1: Location of Mt. Tsukuba and SP survey routes. Thick solid lines: the SP survey routes. A double circle: reference point for SP measurement. Solid circles: locations of DC resistivity survey. Thin solid lines: equi-topographic contour. Gray lines: rivers.

effect on a plutonic mountain. We compare the SP data with hydrological results to discuss main causes of the SP anomalies.

\section{Self-Potential Measurement}

Mt. Tsukuba is located near Tsukuba, central Japan (Figure 1). The maximum altitude is $877 \mathrm{~m}$. The slope gradient is about 20 and 10 degrees at altitude around 500 and 300 meters, respectively. The basement of Mt. Tsukuba mainly consists of granitic rocks, and partly gabbroic rocks and debris [20]. There are many hydrological studies: for example, isotope analysis of river water [21], discharge analysis of river water [22], isotope analysis of spring water, and estimation of water table elevation [23].

SP survey was carried out along eleven routes (A to $\mathrm{K})$ from August 20 to 22 in 2000 (Figure 1). The survey area covers the northern slope of Mt. Tsukuba with altitude range between $130 \mathrm{~m}$ and $780 \mathrm{~m}$. The "leapfrog" method was used for SP observation with electrode spacing of $12-120 \mathrm{~m}$ (mainly $50 \mathrm{~m}$ ). We used two types of paired electrodes and voltmeters as shown in Figure 2. $\mathrm{Cu}-\mathrm{CuSO}_{4}$ electrodes named AUE-type are suitable for the flat soil 


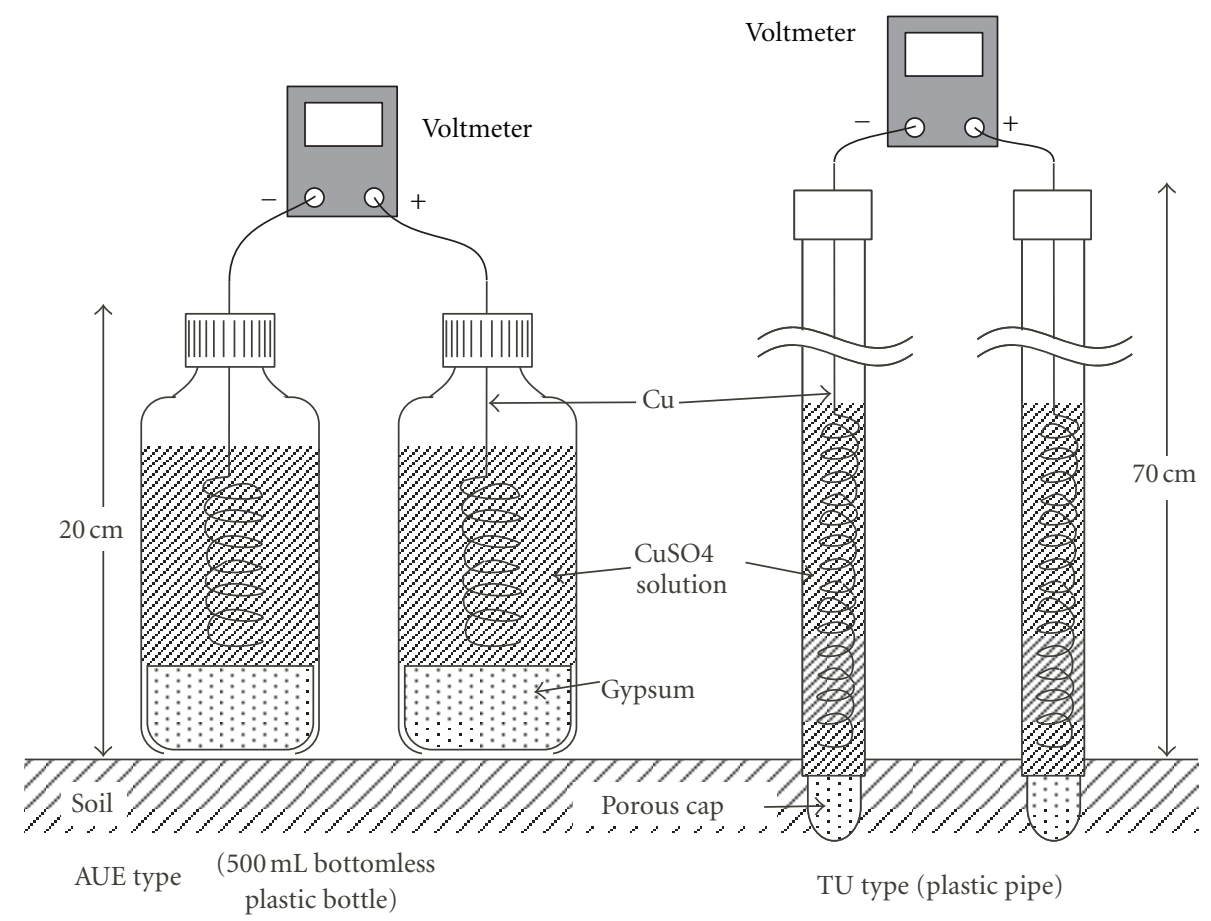

FIgure 2: Schematic diagram of $\mathrm{Cu}-\mathrm{CuSO}_{4}$ electrodes used in this study.

surface, and those named TU-type are used for thick soil cases with stabbing. Electrode position at start or end of each survey route is common among several routes (Figure 1). All observed SP values are represented as relative ones to the reference station near the summit (shown by a double circle in Figure 1).

Stability of the electrode pair was checked by voltage measurement between the two electrodes set on the ground with $10 \mathrm{~cm}$ separation. Such offset check was done at start, end, and several points along each survey route. The offset voltages were within $5 \mathrm{mV}$ in this study. We also confirmed accuracy of the observed SP values by making SP measurements along parallel additional routes (e.g., B, G, H, $\mathrm{C}$, and J-K in Figure 1), whose electrode positions at start and end of profiles were common with main survey routes (A-F in Figure 1).

In addition to SP surveys, DC resistivity surveys were conducted at six sites in this area (Figure 1). A onedimensional forward modeling algorithm [24] and a onedimensional inversion algorithm [25] were applied to obtain near-surface resistivity values. The approximate sounding depth was $10-20 \mathrm{~m}$.

\section{Results}

The observed SP anomalies are shown in Figure 3. Along the main SP profile (A-F), several sharp and local SP anomalies are recognized, in particularly at $770,640,520$, and $360 \mathrm{~m}$ in altitude. Some of the amplitudes exceed $100 \mathrm{mV}$, and the typical altitudinal extent is about $50 \mathrm{~m}$ (corresponding to the horizontal spatial extent of about $150 \mathrm{~m}$ ) or less. As shown in Figure 3(a), similar local SP anomalies are also observed along the neighboring survey routes, $\mathrm{B}, \mathrm{G}$, and $\mathrm{H}$. Note that voltage difference between routes $\mathrm{A}$ and $\mathrm{B}$ was less than $10-20 \mathrm{mV}$, which is thought to be due to small difference (typically less than $\sim 10 \mathrm{~m}$ ) in the electrode position between these two survey routes except the start and end points.

The spectrum analysis gives us more quantitative features of the local and sharp SP anomalies. We applied the fast Fourier transform (FFT) to the obtained SP data along the main profile, A-F. Since the data spacing is not equal through the entire SP profile, we calculated SP values at equispaced points using the natural cubic splines. A linear increasing trend of SP toward the foothill (about $-0.12 \mathrm{mV} / \mathrm{m}$ estimated by the least square regression) is subtracted before the FFT. Finally, the FFT was applied to SP values at 512 points equally spaced with altitude interval of about $1.286 \mathrm{~m}$. The spectrum obtained by the FFT is shown in Figure 4 . Three peaks of spectrum were clearly identified at altitudinal wavelength of $131.6 \mathrm{~m}, 65.8 \mathrm{~m}$, and $43.9 \mathrm{~m}$. To delineate characters of the spectrum peaks in Figure 4 more clearly, we first created a "regional" SP pattern with longer wavelength by applying the inverse FFT to a spectrum portion with longer wavelength (219-658 m) denoted by "A" in Figure 4 and adding the linear trend of SP described above to it. The resultant "regional" SP pattern is shown in Figure 5(a). Then, the "local" SP pattern with shorter wavelength is estimated by subtracting the regional SP pattern from the raw data. Figure 5(b) is the resultant local SP pattern with altitudinal wavelength shorter than $131.8 \mathrm{~m}$. We found that the local SP anomalies have mainly positive peaks with altitudinal extent of $40-60 \mathrm{~m}$. Note that large peaks are obvious at altitudes between $300 \mathrm{~m}$ and $700 \mathrm{~m}$. 


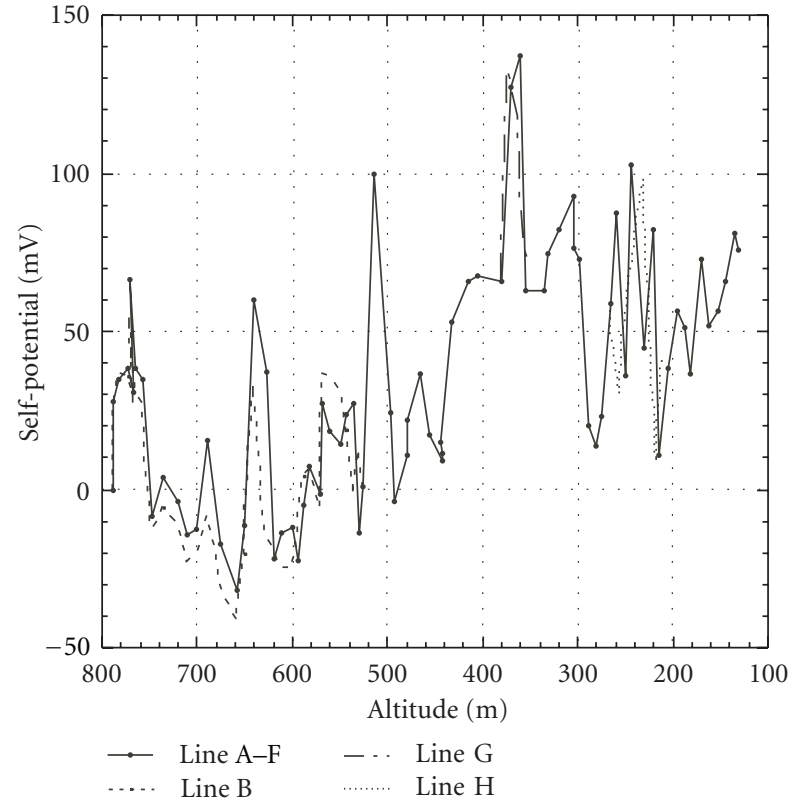

(a)

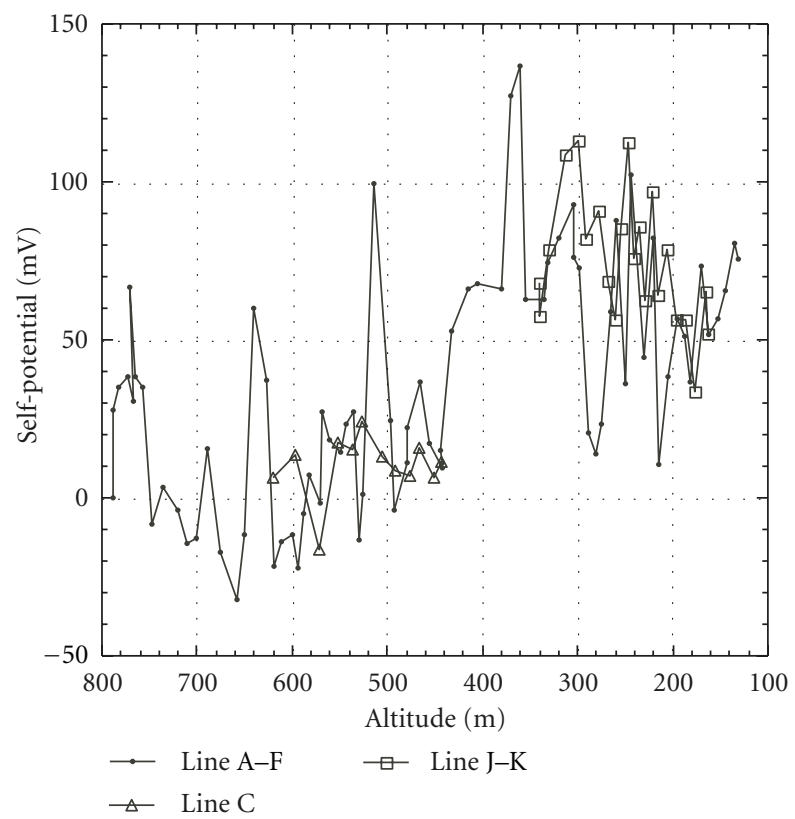

(b)

Figure 3: Observed SP profile along the northern slope of Mt. Tsukuba. (a) Those along the neighboring routes (A, F, B, G, and $\mathrm{H}$ ) and (b) the parallel routes $(\mathrm{C}, \mathrm{J}$, and $\mathrm{K}$ ) are plotted. The reference point is at the summit.

Concerning the longer wavelength (more than $\sim 200 \mathrm{~m}$ in altitude), SP patterns along parallel survey routes show similar features (Figure 3(b)). For example, SP profiles along routes $\mathrm{A}$ and $\mathrm{C}$ are similar to each other except for local SP anomalies described above. The "regional" SP pattern (Figure 5(a)) indicates gradual increase toward the foothill of Mt. Tsukuba. However, the increasing trend is not monotonic and includes two major perturbations. One is

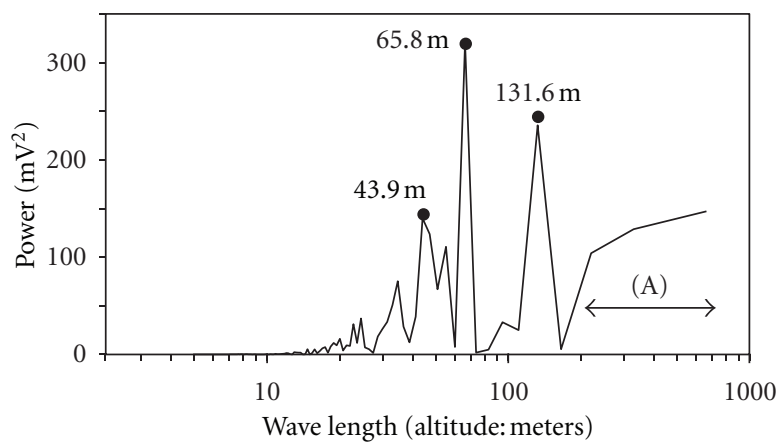

FIgURE 4: Power spectrum of spatial SP distribution against altitude. Three peaks are obvious. Spectrums with longer wavelength are denoted as "A."

a decreasing trend toward lower altitude from $350 \mathrm{~m}$ to $250 \mathrm{~m}$, and another is also a decreasing trend between $750 \mathrm{~m}$ and $650 \mathrm{~m}$ in altitude. The former decreasing trend is also recognized along parallel route J-K (Figure 3(b)), suggesting that this decreasing trend has substantial spatial extent in the same altitudes.

\section{Discussion}

4.1. Local SP Anomalies. "Local" SP anomalies of positive polarity (Figure 5(b)) have a limited spatial extent. The altitudinal extent of them is typically about $40-60 \mathrm{~m}$, which corresponds to horizontal extent of 100-200 m (because of 10-20 degrees slope gradient). In order to estimate the approximate depth of electrical current source which generates such local SP anomalies, simple calculations were conducted. A point current source was assumed in a uniform resistivity $(\rho)$ half-space. The depth of point source $(d)$ was varied, and the surface potential field $(V)$ was calculated using the following simple analytic solution:

$$
V=\frac{\rho \cdot I}{2 \pi \sqrt{r^{2}+d^{2}}}
$$

where $r$ is the horizontal distance between the source and the observation point, and $I$ is the source current strength. The calculated potential profile with respective source depths is normalized by the SP value at $r=0 \mathrm{~m}$ (shown in Figure 6). For comparison between the calculated and observed SP, we plot two local SP anomalies (denoted by "A" and " $B$ " in Figure 5(b)) in Figure 6. Zero level is fixed as an average SP values at the northern and southern edges of each anomaly, and SP values are normalized by the peak values. On the basis of Figure 6, the sources for local SP anomalies are thought to be located near the surface; we roughly estimate the depths to be shallower than $\sim 10$ meters, although the observed local SP values are substantially scattered.

A cause of local positive SP anomalies such as observed in the present study is generally inferred to be local springs, yielding a positive current source near the ground surface. The slope of Mt. Tsukuba is widely covered by debris or slope deposits, which consist of unconsolidated sediments and have high permeability. It is well known that perched 


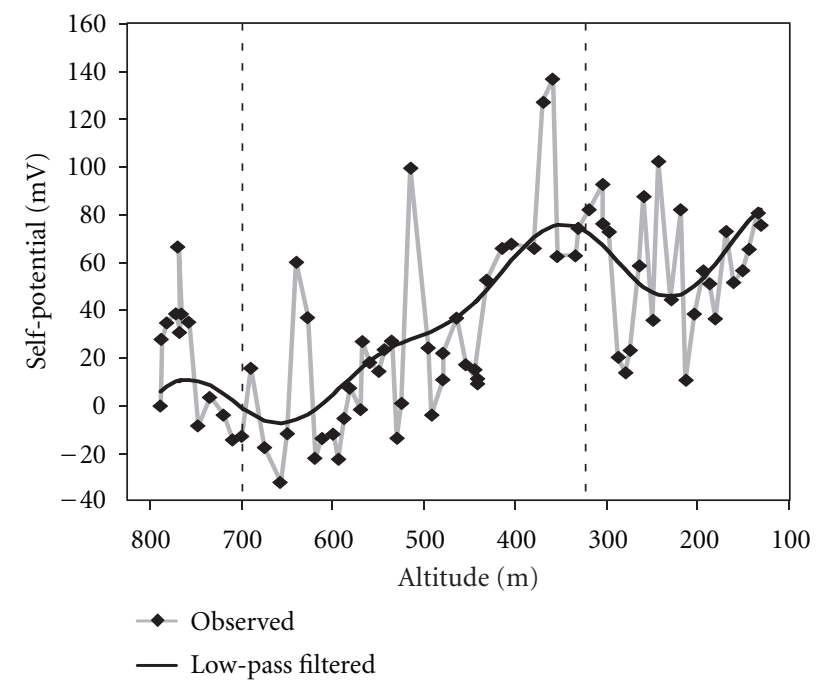

(a)

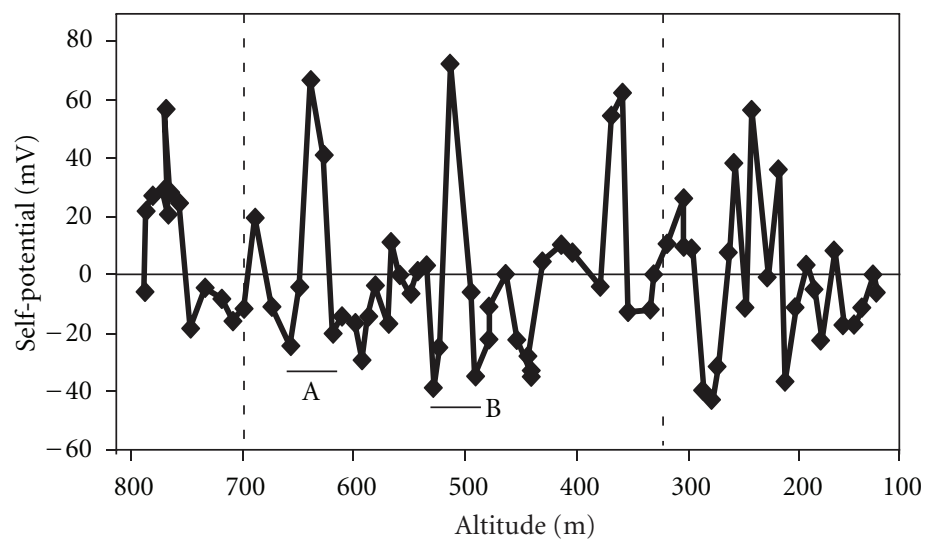

(b)

FIGURE 5: (a) The observed raw SP profile (gray line with diamonds) and low-pass filtered one called as "regional" pattern in this study (solid line). (b) Residual SP profile after subtracting regional SP from raw data, called as "local" anomalies.

water flow is present in a vadose zone developed in such slope deposits; therefore, we infer that the observed local SP anomalies reflect discharge of perched water. However, most of the anomalies are not located in the neighbor (within a few ten meters) of known springs. So instead of directly corresponding to surface springs, the current sources are thought to be located at underground transition zone of electrokinetic coupling coefficient where perched water flow loses its ability to carry electrical charges with it. In the area with altitude higher than about $450 \mathrm{~m}$, the slope angle increases gently toward the summit (from 10 to 20 degrees), and larger gravels are conspicuous. May be, perched water flow becomes stream-like flow through underground channels (cavities), which does not transport sufficient electrical charges with it unlike the flow through porous media, at shallower depths than $\sim 10$ meters in the slope deposits. Such underground streams may start from the locations of local SP anomalies like "A" and "B" shown in Figure 5(b) and flow into nearby rivers. Anyway, such shallow phenomena seem to show seasonal variations. We will need to make repeated measurements to observe a correlation with precipitation, and so forth in the future.

4.2. Regional SP Pattern. The general trend of "regional" SP pattern indicates gradual increase toward the foothill of Mt. Tsukuba (Figure 5(a)). This is a typical example of the topographic effect on SP, interpreted by the mountainscale groundwater flow from summit to foothill. The mean coefficient of topographic effect was about $-0.12 \mathrm{mV} / \mathrm{m}$, and the maximum was about $-0.45 \mathrm{mV} / \mathrm{m}$ at altitude of $400 \mathrm{~m}$. It is noteworthy that the measured streaming potential coefficient for intact rock samples of Inada granite is about $0.03 \times 10^{-6} \mathrm{~V} / \mathrm{Pa}$ for $0.001 \mathrm{~mol} / \mathrm{L} \mathrm{KCl}$ solution below $50^{\circ} \mathrm{C}$ $[26,27]$. If we apply this data to the granitic basement of Mt. Tsukuba, topographic effect of $-0.3 \mathrm{mV} / \mathrm{m}$ is possible for the case that water table is located close to the upper surface of the granitic basement (Figure $7(\mathrm{a})$ ). Substantial part of the general trend is thought to be caused by the water flow in the granitic basement. 


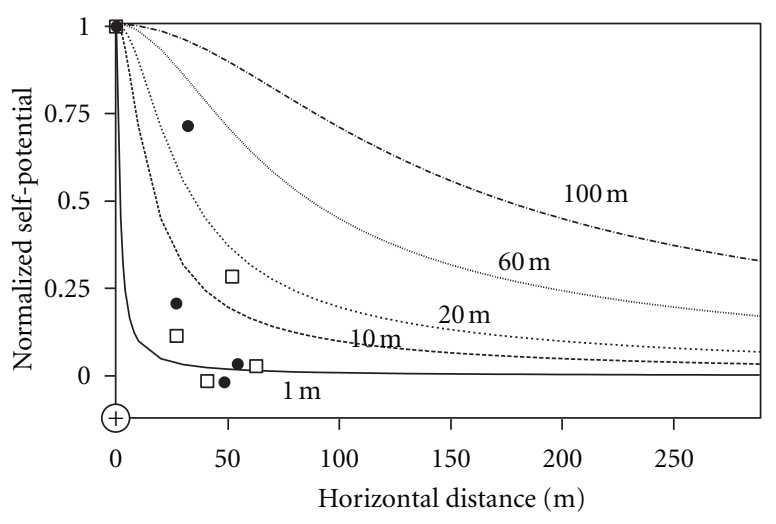

FIGURE 6: Calculated SP from various depths of a point source (1$100 \mathrm{~m}$ ). The SP values are normalized by the respective value at $0 \mathrm{~m}$ in the horizontal distance where the source is located. The observed SP anomalies "A" and "B" in Figure 5(b) are shown by circles and rectangles, respectively.

There are two major perturbations from the general trend as mentioned in Section 3. Both of them seem to be present near geological contacts between different units along the mountain slope. The Holocene younger slope deposits (unconsolidated sediments) distribute below altitude of $320 \mathrm{~m}$ along the route $\mathrm{F}$, while the Holocene older slope deposits distribute around altitude of 320-700 m (Figure 7(a)). Above $700 \mathrm{~m}$ in altitude, the gabbro basement rock is exposed with a cap-like distribution around the summit [20]. Two decreasing patterns toward the foothill ("RA" and "RB" in Figure 7(b)), which are inconsistent with the ordinal topographic effect, are located near these geological boundaries at the ground surface. In the following, we discuss causes of these two perturbations based upon the heterogeneity of subsurface structure and related groundwater flow.

4.2.1. Regional SP Perturbation at the Foot Hill. The decreasing pattern "RA" in Figure 7(b) is present near the boundary between older and younger slope deposits as mentioned above. One of the candidates for this perturbation is a difference in the coupling coefficient between the two deposits. Even though both slope deposits have the same material origin (gabbro and granite), the coupling coefficient may be different between them due to difference in the formation factor (porosity, tortuosity), and so forth (e.g., [6]). In addition to this, hydrological heterogeneities such as water table perturbation due to heterogeneous permeability distribution and heterogeneous infiltration of meteoric water can be candidates.

If the younger slope deposits (on the lower altitude side) are more permeable than the older slope deposits (on the higher altitude side), downward fluid flow crossing the boundary leaves positive charges there (with negative zeta potential) due to discontinuous pressure gradient normal to the boundary even if the coupling coefficient is homogeneous [28]. However, it depends on the hydrological boundary condition at the ground surface whether or not water flow though a heterogeneous permeability region
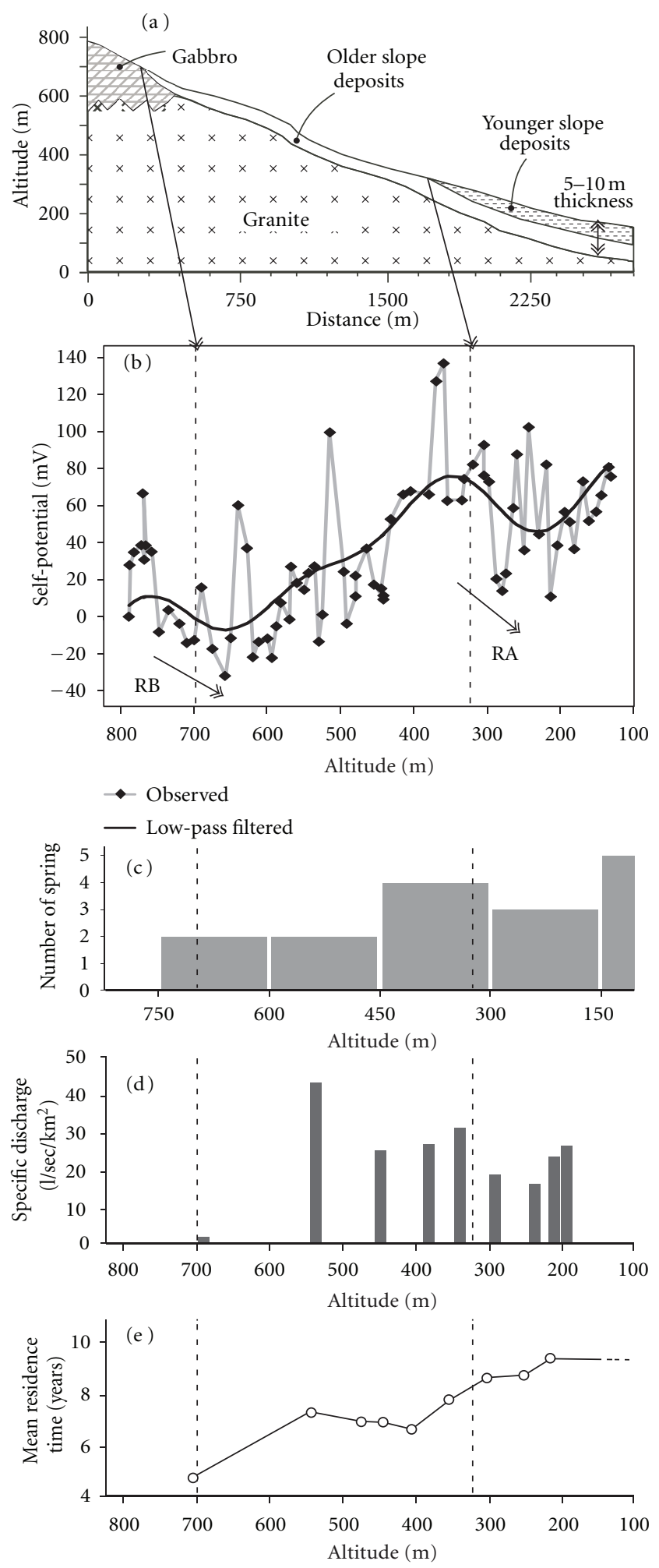

FIGURE 7: Comparison of the geological setting, SP distributions, and hydrological information along the northern slope of Mt. Tsukuba. (a) Geological structure [20]. Note that the surface layer is exaggerated vertically. (b) Raw and regional SP profiles are same as shown in Figure 5. (c) Histogram for number of springs around Mt. Tsukuba against altitude derived from [23]. (d) Specific discharge of the Ono-kawa river water [22]. (e) Mean residence time of stream water [21]. 
brings about surface SP anomalies. If it is pressure (hydraulic head) = constant, no SP anomaly will appear at the ground surface. Electrical charges appearing at the permeability boundary just work as sources to create potential distribution corresponding to the distorted pressure distribution at the boundary (see the tutorial by Jouniaux and Ishido [29], in this special issue "Electrokinetics in Earth Sciences" for more details). However, if the impermeable boundary condition (Neumann condition) is adopted, surface SP anomalies will appear corresponding to hydraulic head distribution along the surface boundary which is modified as a result of heterogeneous permeability distribution (T. Ishido, pers. comm., 2012). The effects of permeability heterogeneity on SP pattern are studied by Ozaki et al. [30]. In their numerical simulation using two-dimensional FDM (finite difference method), the Neumann boundary condition was adopted: no flow normal to all exterior boundaries of the model domain including the ground surface. In the present case (Figure 7(a)), water table (hydraulic head) will be lowered near the boundary between the younger and older slope deposits if the permeability is larger for the younger deposits. Since the lower water table corresponds to higher SP (e.g., $[10,11])$, the observed decreasing trend "RA" toward the foothill cannot be explained by this mechanism.

Next, the possibility of heterogeneous infiltration is discussed hereinafter on the basis of a lot of hydrological information. Histogram of number of springs against altitude is made from a distribution of springs in the whole area of Mt. Tsukuba [23]. The histogram shown in Figure 7(c) indicates a clear correlation with the regional SP pattern. The higher SP value is, the more frequently springs are found. A distribution of specific discharge of river water also indicates a high correlation with the regional SP pattern around the foothill. Specific discharge is a flow rate of river water normalized by the catchment area and reflects the contribution of groundwater discharges into river water. Figure $7(\mathrm{~d})$ is the observation result along the Ono-kawa River [22]. Lower specific discharges around $250 \mathrm{~m}$ altitude compared to those around $350 \mathrm{~m}$ altitude indicate that groundwater discharges into river water are relatively small in the catchment area around $250 \mathrm{~m}$ altitude. This means that the fraction of downward groundwater infiltration is relatively high around $250 \mathrm{~m}$ altitude compared to the area around $350 \mathrm{~m}$ altitude. This is consistent with the result of isotopic analysis [21]; the stream water shows relatively old and young ages at altitudes around $250 \mathrm{~m}$ and $350 \mathrm{~m}$, respectively (Figure $7(\mathrm{e})$ ). This means that the contribution of shallow groundwater originating from recent rainfalls to groundwater discharges is relatively small around $250 \mathrm{~m}$ altitude compared to that around $350 \mathrm{~m}$ altitude. These hydrological data imply that the vadose zone is relatively thick and thin at altitudes of $250 \mathrm{~m}$ and $350 \mathrm{~m}$, respectively.

Our DC resistivity survey supports this implication; the average resistivity of the older slope deposits is 100 $200 \Omega \mathrm{m}$, while it is higher $(200-500 \Omega \mathrm{m})$ in the younger slope deposits, suggesting a highly unsaturated condition. Therefore, we may conclude that the SP decreasing pattern at the foothill ("RA" in Figure 7(b)) is mainly generated by vertical infiltration flow through the thicker vadose zone in the younger slope deposits and underlying layers. If the thickness of the vadose zone is comparable to that of the younger slope deposits (less than 10 meters, Figure $7(a)$ ), the vertical potential gradient in the vadose zone needs to be around $-3 \mathrm{mV} / \mathrm{m}$ to explain the regional negative SP at altitude of $250 \mathrm{~m}$. This gradient $(-3 \mathrm{mV} / \mathrm{m})$ is an order of magnitude greater than the observed general topographic effect, which suggests that the effective streaming potential coefficient of the vadose zone in the younger slope deposits is significantly larger in magnitude than that of the surrounding area.

4.2.2. Regional SP Perturbation Near the Summit. The decreasing pattern "RB" in Figure $7(b)$ is present at the lower perimeter of the gabbro rock body exposed around the summit. Water table around the summit is estimated to be quite deep and almost flat based on a hydrological study with isotope analysis and numerical modeling of groundwater flow [23]. The water table is located below the gabbroic body in the granitic basement at higher elevation areas than about $500 \mathrm{~m}$, and the thickness of vadose zone is more than $200 \mathrm{~m}$ around the boundary between the gabbroic rocks and the slope deposits at $\sim 700 \mathrm{~m}$ altitude (Figure $7(\mathrm{a})$ ). In order to discuss the main causes of the SP perturbation, we carried out a simple numerical modeling by assuming electrical current sources as shown in Figure 8.

The intensity of the current sources is given from the streaming current density $J$ (in $\mathrm{A} / \mathrm{m}^{2}$ ) in the vadose zone (e.g., [11]):

$$
J=-L \rho g \nabla h,
$$

where $L$ is the electrokinetic coupling coefficient for the vadose zone (in $\mathrm{A} / \mathrm{Pa}-\mathrm{m}$ ), $\rho$ is the liquid water density $\left(\sim 10^{3} \mathrm{~kg} / \mathrm{m}^{3}\right), g$ is the gravitational acceleration $\left(9.8 \mathrm{~m} / \mathrm{sec}^{2}\right)$, and $h$ is the hydraulic head (in meter). As for vertical infiltration of water in the vadose zone, $\nabla h$ can be assumed to be $\sim 1$. Although experimental data of $L$ was reported for unsaturated sands (e.g., [31]), no data is available for liquid/gas two-phase flow in the granitic rocks. We simply assume $L=-2 \times 10^{-10} \mathrm{~A} / \mathrm{Pa}-\mathrm{m}$ for the vadose zone in the present calculation, which means $|J|=2 \times 10^{-6} \mathrm{~A} / \mathrm{m}^{2}$ from (2). In all of the three models shown in Figure 8, the intensity of unit current source at the ground surface is given as $I=-0.002 \mathrm{~A}$ for a surface area of $20 \mathrm{~m}$ (along the slope) $\times 50 \mathrm{~m}$ (perpendicular to the slope). Such current sources are assumed every $20 \mathrm{~m}$ between $0 \mathrm{~m}$ and $400 \mathrm{~m}$ along the slope, and current sources of the same intensity but with opposite sign $(I=+0.002 \mathrm{~A})$ are assumed every $20 \mathrm{~m}$ along the water table for charge conservation. As for the streaming current density in the underlying saturated region, we assume relatively large magnitude $\left(|J|=4 \times 10^{-6} \mathrm{~A} / \mathrm{m}^{2}\right.$, which may be too large considering a small $\nabla h$ value for the saturated region, T. Ishido, pers. comm., 2012). Thus, negative current sources (unit intensity of $-0.004 \mathrm{~A}$ ) are assumed every $20 \mathrm{~m}$ along the water table, and a positive current source of $+0.08 \mathrm{~A}(=0.004 \mathrm{~A} \times 20)$ is assumed for charge conservation on the slope surface (at $700 \mathrm{~m}$ foothill side from the origin of slope). A three-dimensional forward calculation code "3ddcxh" [32] is used to calculate the SP, 


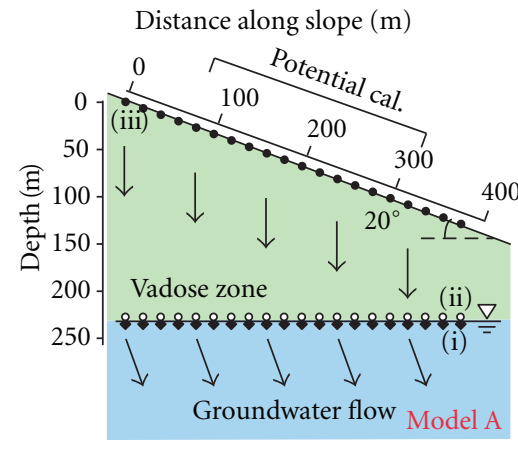

(a)

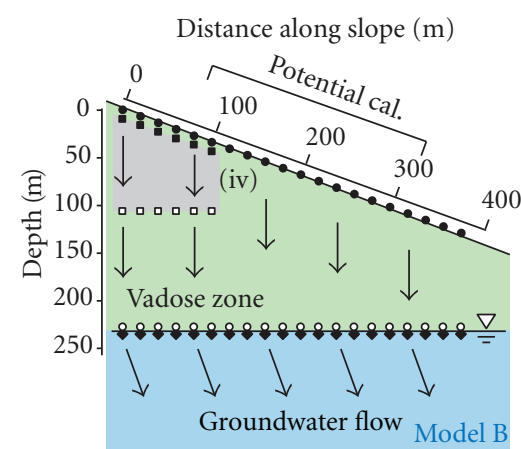

(b)

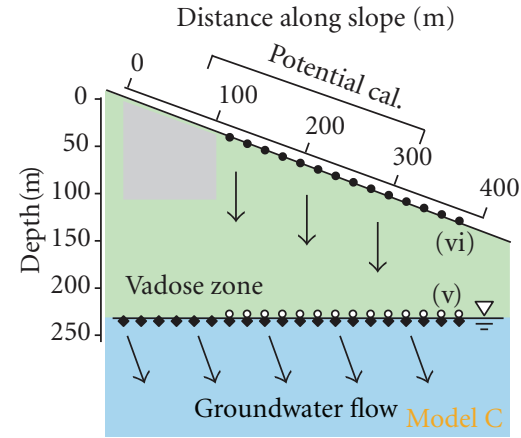

(c)

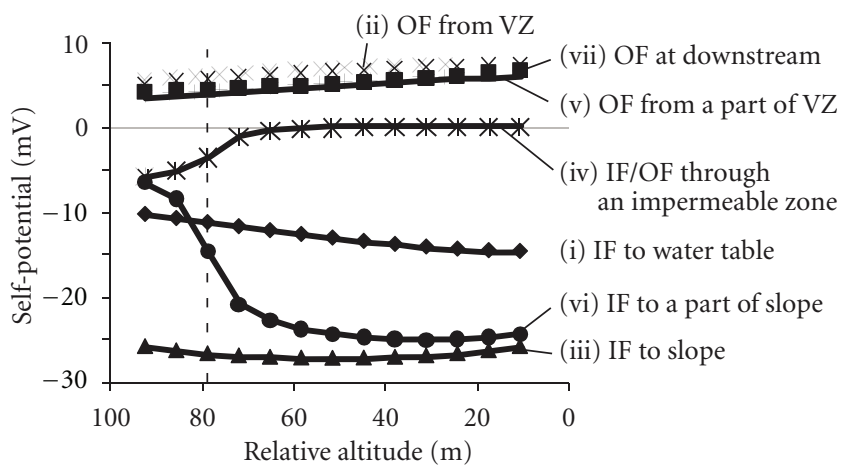

(d)

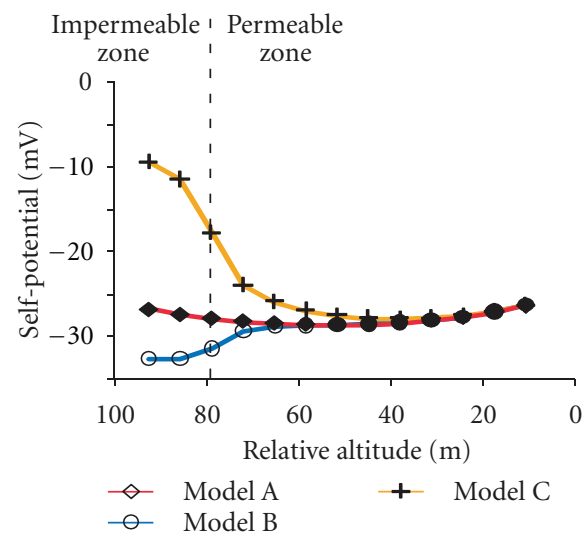

(e)

Figure 8: Numerical modeling of SP profiles along slopes. (a) Model A with homogeneous subsurface structure. (b) Model B with constant infiltration through both a less permeable zone (gray) and surroundings. (c) Model C with heterogeneous infiltration outside of an impermeable zone (gray). In all three models, diamonds, circles, and rectangular dots indicate electric current sources with intensity of $0.004,0.002$, and $0.001 \mathrm{~A}$, respectively. Solid and open symbols mean negative and positive polarities, respectively. Arrows indicate assumed flow directions. SP profiles shown in (d) and (e) are calculated along the thick line portion on the slope for each case. (d) Calculated SP from respective current sources. The abbreviations are as follows: IF: inflow, OF: outflow, and VZ: vadose zone. (e) Resultant SP profiles from three models against altitude.

assuming a uniform subsurface resistivity of $200 \Omega \mathrm{m}$ (which is estimated from the DC resistivity survey).

As shown in Figure 8, we consider three models: (A) with homogeneous permeability and infiltration, (B) with a less permeable zone (gabbro) and homogeneous infiltration, and (C) with an impermeable zone (gabbro) and heterogeneous infiltration. The SP from model A (Figure 8(a)) is regarded as a reference without heterogeneity, which shows almost flat profile (Figure $8(\mathrm{e})$ ). The reason why a negative correlation between SP and altitude is not seen here is due to the effect of intense negative current sources assigned to mimic downward saturated water flow along the water table (see the curve (i) in Figure 8(d)). In model B (Figure 8(b)), the streaming current density is assumed to be $|J|=3 \times$ $10^{-6} \mathrm{~A} / \mathrm{m}^{2}$ for the gabbroic body, that is, one and half times that for the surrounding vadose zone (this assumption may be plausible considering that the liquid-phase saturation can be higher in the less permeable zone). This assumption produces a negative SP near the summit (see the curve (iv) in Figure 8(d)), which results in an opposite feature to the observation (Figure 8(e)). In model C (Figure 8(c)), no infiltration is assumed along the gabbroic rock surface, considering a situation that most of rainfall water is removed from the area due to rapid runoff along the almost impermeable rock surface and does not infiltrate downward. Due to this effect (see the curve (vi) in Figure 8(d)), the SP profile (shown in Figure 8(e)) shows a corresponding trend to the observed SP with decreasing pattern near the summit ("RB" in Figure 7(b)).

As a result of the above calculations, the heterogeneous infiltration at the surface is thought to be the most probable cause of the SP perturbation observed near the summit. A similar but more prominent feature observed near active volcano summits has been studied by numerical simulations (e.g., $[14,33]$ ). Aizawa et al. [33] carried out a sophisticated modeling of both groundwater flow and SP and indicates that a heterogeneous infiltration due to a less permeable zone near the summit makes regional "sink" pattern of SP along the mountain slope. In their study, heterogeneous distributions of coupling coefficient and electrical conductivity are taken into account in addition to permeability heterogeneity. The presence of extensive alteration rocks around volcano 
summits is very influential on the SP distribution due to its high electrical conductivity rather than its impervious nature [14]. In such situations, we need to take into account various factors other than heterogeneous permeability and infiltration distributions.

In field observations, similar SP patterns are also found at small-scale mountain slopes. For example, in the Nagano prefecture, Japan, Abe [22] found the relatively positive SP anomaly near a ridge and negative "sink" SP pattern off the ridge. We suppose that the ridge areas have a thin permeable layer at the surface, and infiltration mainly occurs off the ridge having a thicker surface permeable layer. We believe that this phenomenon is rather common at many mountain slopes, so it is very important to take into account heterogeneous infiltration effects to discuss groundwater flow systems beneath mountain slopes.

\section{Summary}

On the basis of the proposed causes for local and regional SP patterns in this study, we summarize the inferred groundwater flow system in Mt. Tsukuba. As discussed in Section 4.2.1, the water table comes close to the surface at altitude of about $400 \mathrm{~m}$, inferred by the high regional SP values, the younger mean residence time of stream water, and distribution of springs (Figures 7(b), 7(e), and 7(c)). The water table goes down at the foothill (lower than $350 \mathrm{~m}$ in altitude) covered by thick younger slope deposits with high permeability, inferred by the regional SP sink pattern "RA" and the specific discharge of stream (Figures 7(b) and $7(d))$. The thickness of the vadose zone will be over $10 \mathrm{~m}$ estimated by the DC resistivity survey. Around the summit, as discussed in Section 4.2.2, the thicker vadose zone expands above the water table located in the granitic basement. The infiltration is not homogeneous with simple vertical flow but is concentrated outside of the gabbro rocks at the summit, inferred from the regional SP pattern "RB" near the summit (Figure 7(b)). In addition to the regional flow systems, local flow of perched water is developed in the vadose zone in the slope deposits as discussed in Section 4.1. The local positive SP anomalies (Figure 5(b)) are thought to be associated with outflow of perched water near the ground surface.

The implication for groundwater flow system in Mt. Tsukuba is not solely derived from hydrological information. The combination of hydrological and SP surveys gives us a chance of sophisticated interpretation of groundwater flow system. The major contribution of SP surveys comes from wider spatial coverage with high measurement density than the conventional hydrological surveys along the mountain slope. On the other hand, SP data alone is not interpreted uniquely among various possible patterns of groundwater flow. Therefore, SP surveys are brought into a complementary relation with hydrological information. In the future, coupled numerical examinations of both groundwater flow and SP should be performed for many cases along mountain slopes, which is very helpful in evaluation of groundwater flow systems for environmental, engineering, agricultural, and scientific issues.

\section{Acknowledgments}

The authors thank Dr. Y. Tanaka, Dr. Y. Sasai, and Dr. H. Murakami for their valuable comments about field experiments. They thank Yumiko Tsutsui, Takuya Omura, Takayuki Kimura, Chisa Kobayashi, and Manabu Shibata for their help on preexperiments. This paper has been greatly improved by constructive remarks from the Academic Editor Dr. Tsuneo Ishido and two anonymous reviewers. This work was partially supported by a Grant for Scientific Research from the Ministry of Education, Japan (no. 23501241).

\section{References}

[1] D. B. Jackson and J. Kauahikaua, "Regional self-potential anomalies at Kilauea Volcano ( Hawaii)," US Geological Survey Professional Paper, vol. 1350, no. 2, pp. 947-959, 1987.

[2] F. S. Birch, “Testing Fournier's method for finding water table from self-potential," Ground Water, vol. 31, pp. 50-56, 1993.

[3] Y. Sasai, J. Zlotnicki, Y. Nlshida et al., "Electromagnetic monitoring of miyake-jima volcano, izu-bonin arc, japan: a preliminary report," Journal of Geomagnetism and Geoelectricity, vol. 49, no. 11-12, pp. 1293-1316, 1997.

[4] T. Ishido, "Self-potential generation by subsurface water flow through electrokinetic coupling, in Detection of subsurface flow phenomena," Lecture Notes in Earth Sciences, vol. 27, pp. 121-131, 1989.

[5] A. Revil and P. Leroy, "Hydroelectric coupling in a clayey material," Geophysical Research Letters, vol. 28, no. 8, pp. 16431646, 2001.

[6] T. Ishido and J. Muzutani, "Experimental and theoretical basis of electrokinetic phenomena in rock-water systems and its applications to geophysics," Journal of Geophysical Research, vol. 86, no. 3, pp. 1763-1775, 1981.

[7] K. Yasukawa and T. Mogi, “Topographic effects on Sp anomaly caused by subsurface fluid flow-numerical approach," Butsuri-Tansa, vol. 51, pp. 17-26, 1998.

[8] R. F. Corwin and D. B. Hoover, "Self-potential method in geothermal exploration," Geophysics, vol. 44, no. 2, pp. 226$245,1979$.

[9] F. Timm and P. Möller, "The relation between electric and redox potential: evidence from laboratory and field measurements," Journal of Geochemical Exploration, vol. 72, no. 2, pp. 115-128, 2001.

[10] C. Fournier, "Spontaneous potentials and resistivity surveys applied to hydrogeology in a volcanic area: case history of the Chaine des Puys (Puy-de-Dome, France)," Geophysical Prospecting, vol. 37, no. 6, pp. 647-668, 1989.

[11] A. Revil, V. Naudet, and J. D. Meunier, "The hydroelectric problem of porous rocks: inversion of the position of the water table from self-potential data," Geophysical Journal International, vol. 159, no. 2, pp. 435-444, 2004.

[12] N. Linde, A. Revil, A. Bolève et al., "Estimation of the water table throughout a catchment using self-potential and piezometric data in a Bayesian framework," Journal of Hydrology, vol. 334, no. 1-2, pp. 88-98, 2007.

[13] M. Aubert and Q. Yéné Atangana, "Self-potential method in hydrogeological exploration of volcanic areas," Ground Water, vol. 34, no. 6, pp. 1010-1016, 1996.

[14] T. Ishido, "Electrokinetic mechanisms for the "W"-shaped self-potential profile on volcanoes," Geophysical Research Letters, vol. 31, no. 15, pp. L15616-5, 2004. 
[15] K. Ernstson and H. U. Scherer, "Self-potential variations with time and their relation to hydrogeologic and meteorological parameters," Geophysics, vol. 51, no. 10, pp. 1967-1977, 1986.

[16] C. J. Zablocki, "Some electrical and magnetic studies of Kilauea Iki lava lake," Open-File Report-U. S. Geological Survey, Report OF 76-0304, Hawaii, USA, 1976.

[17] F. Massenet and P. Van Ngoc, "Mapping and surveillance of active fissure zones on a volcano by the self-potential method, Etna, Sicily," Journal of Volcanology and Geothermal Research, vol. 24, no. 3-4, pp. 315-338, 1985.

[18] J. Zlotnicki, M. Feuillard, and G. Hammouya, "Water circulations on La Soufriere volcano inferred by self- potential surveys (Guadeloupe, Lesser Antilles). Renewal of volcanic activity?" Journal of Geomagnetism \& Geoelectricity, vol. 46, no. 9, pp. 797-813, 1994.

[19] T. Hashimoto and Y. Tanaka, "A large self-potential anomaly on Unzen volcano, Shimabara Peninsula, Kyushu Island, Japan," Geophysical Research Letters, vol. 22, no. 3, pp. 191194, 1995.

[20] S. Igi, Geologic Atlas of Japan Kanto Region, Asakura Shoten, Tokyo, Japan, 1990.

[21] K. Sanjo, "Isotope hydrology of Mt. Tsukuba," Science Reports-University of Tsukuba, Institute of Geoscience, Section A, vol. 12, pp. 1-36, 1991.

[22] Y. Abe, Estimation of groundwater flow using self-potential measurement in hillslopes of College of Natural Sciences, Graduation thesis, First Cluster of Colleges, University Tsukuba, 2001.

[23] T. Matsumoto, Age dating of spring and groundwater and its modeling in Mt. Tsukuba, central Japan, M.S. thesis, University Tsukuba, 2011.

[24] Y. Murakami, "Computer program for processing and interpreting Schlumberger and Wenner resistivity data," Open File Report number 42, Geological Survey of Japan, 1987.

[25] K. Ushijima, H. Mizunaga, and A. Kato, "Interpretation of geoelectric sounding data by personal computer," ButsuriTanasa, vol. 40, pp. 423-435, 1987.

[26] T. Tosha, N. Matsushima, and T. Ishido, "Zeta potential measured for an intact granite sample at temperatures to $200^{\circ}$ C," Geophysical Research Letters, vol. 30, no. 6, pp. 28-1, 2003.

[27] T. Ishido and N. Matsushima, "Streaming potential measured for an intact granite sample at temperatures to $200^{\circ} \mathrm{C}$," in Proceedings of the 32nd Workshop on Geothermal Reservoir Engineering, 2007, SGP-TR-183, Stanford University.

[28] W. R. Sill, "Self-potential modeling from primary flows," Geophysics, vol. 48, no. 1, pp. 76-86, 1983.

[29] L. Jouniaux and T. Ishido, "Electrokinetics in earth sciences: a tutorial," International Journal of Geophysics, vol. 2012, Article ID 286107, 2012.

[30] Y. Ozaki, H. Mikada, T. Goto, J. Takekawa, M. Tsujimura, and F. Hachani, "Effect of heterogeneity of hydraulic conductivity on streaming potential," in Proceedings of the 14th International Symposium on Recent Advances in Exploration Geophysics (RAEG'10), pp. 115-117, 2010.

[31] X. Guichet, L. Jouniaux, and J. P. Pozzi, "Streaming potential of a sand column in partial saturation conditions," Journal of Geophysical Research B, vol. 108, no. 2141, p. 2, 2003.

[32] K. Spitzer, "A 3-D finite-difference algorithm for DC resistivity modelling using conjugate gradient methods," Geophysical Journal International, vol. 123, no. 3, pp. 903-914, 1995.
[33] K. Aizawa, Y. Ogawa, and T. Ishido, "Groundwater flow and hydrothermal systems within volcanic edifices: delineation by electric self-potential and magnetotellurics," Journal of Geophysical Research B, vol. 114, no. 1, Article ID B01208, 2009. 

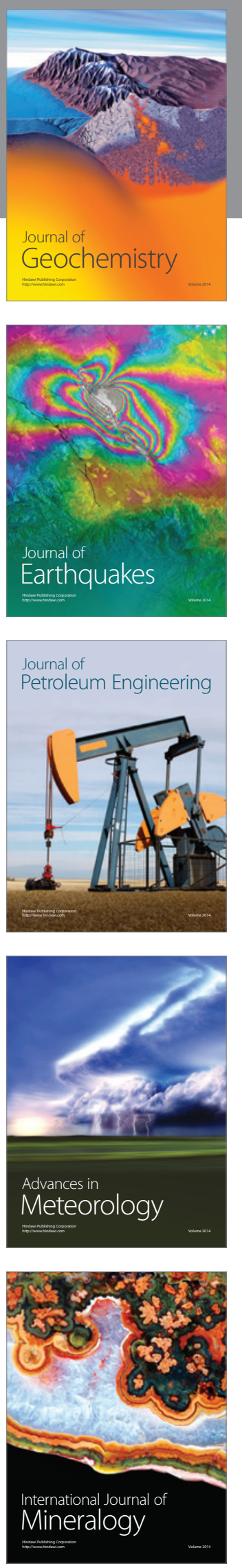
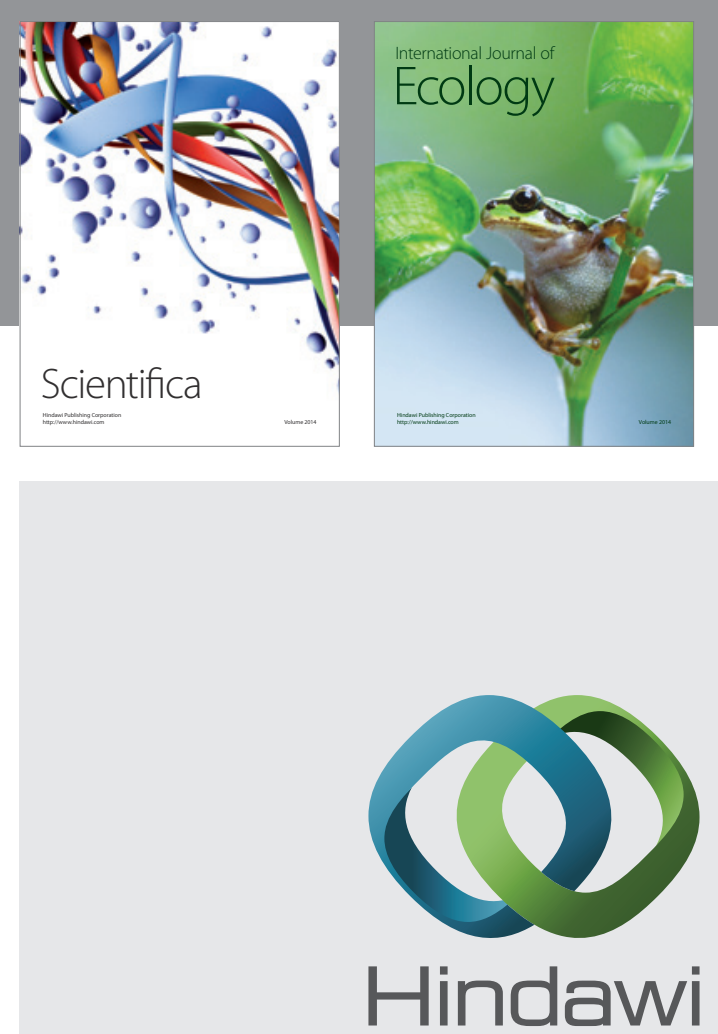

Submit your manuscripts at http://www.hindawi.com
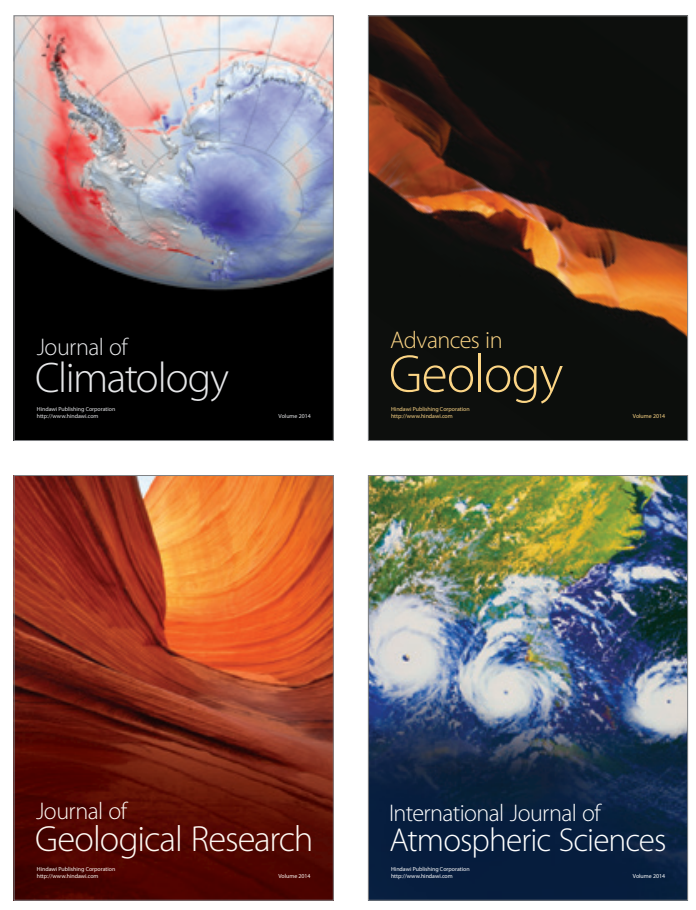
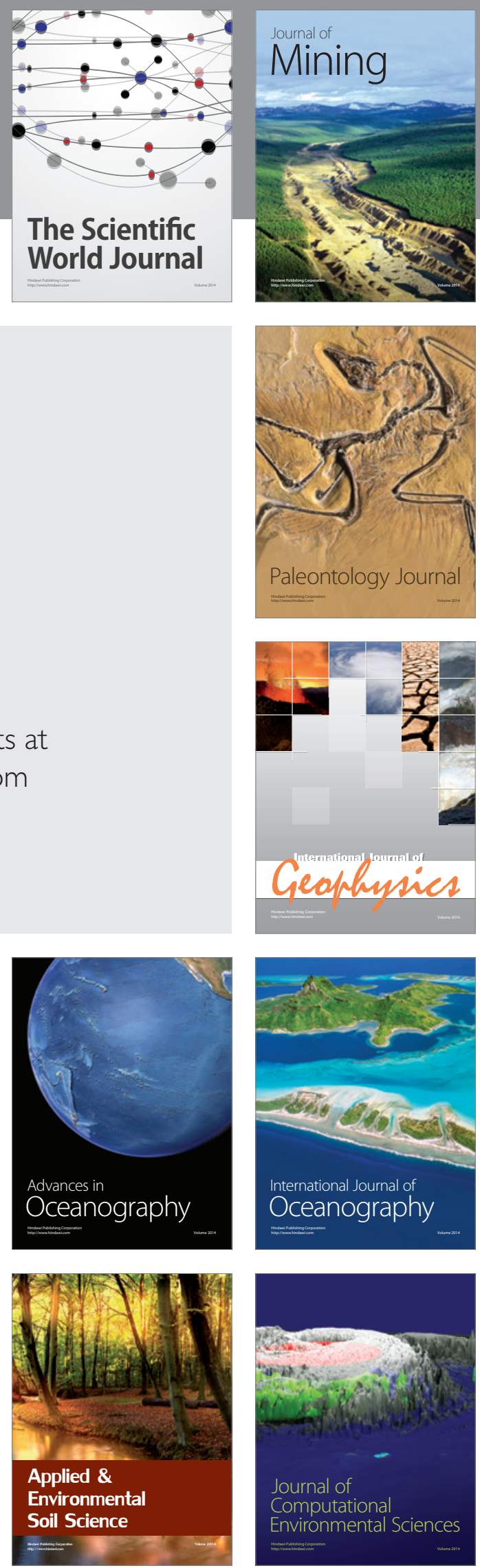